\title{
SOROPREVALÊNCIA DO Toxoplasma gondii EM GALINHAS (Gallus gallus domesticus) DE CRIAÇÕES DOMÉSTICAS, ORIUNDAS DE PROPRIEDADES RURAIS DO NORTE DO PARANÁ, BRASIL ${ }^{1}$
}

\section{SEROPREVALENCE OF Toxoplasma gondii IN BACK YARD CHICKEN (Gallus gallus domesticus) FROM RURAL PROPERTIES IN NORTH REGION OF PARANÁ STATE, BRAZIL}

\author{
João Luis Garcia ${ }^{2}$ Italmar Teodorico Navarro $^{3}$ Liza Ogawa $^{4}$ \\ Elisabete Regina Marangoni Marana ${ }^{5}$
}

RESUMO

O Toxoplasma gondii é um protozoário que pode infectar todos os animais homeotérmicos. No presente trabalho, verificou-se a ocorrência de anticorpos anti-T. gondii em galinhas de criações domésticas (fundo de quintal), oriundas de propriedades rurais localizadas no município de Jaguapitã, Estado do Paraná, Brasil. Estudos prévios demostraram que o parasita está amplamente disseminado nas diferentes espécies de animais domésticos, de companhia e no homem nessas mesmas propriedades. Os soros foram submetidos à reação de Imunofluorescência Indireta, sendo a positividade considerada para àqueles títulos maiores ou iguais a 16. Foram estudados 155 soros, sendo que 16 (10,3\%) foram reagentes à toxoplasmose, e 139 $(89,7 \%)$ não reagentes. Os títulos mais freqüentes foram de 64 (5/31,2\%), 16 e 1024 (ambos com 4/25\%) e o maior título encontrado foi de 1024 (4/25\%). A soroprevalência do T. gondii não foi influenciada pelo sexo da ave (Exato de Fisher $p=0,12$ ), pela finalidade da criação (corte ou postura, Exato de Fisher $p=$ $0,39)$, pela percentagem de felinos sororeagentes na propriedade $(r=-0,19 p=0,27)$, nem pelo número de felinos sororeagentes $(r$ $=-0,09 p=0,60)$. Através do presente trabalho, demostrou-se uma ocorrência elevada da resposta sorológica ao $\boldsymbol{T}$. gondii em aves domésticas oriundas de propriedades rurais neste município, conseqüentemente esses animais podem representar risco de infecção para o homem e para outros animais quando consumidos crus ou mal cozidos.

Palavras-chave: toxoplasmose em aves, soroprevalência, soroepidemiologia, Toxoplasma gondii.

\section{SUMMARY}

Toxoplasma gondii is a protozoa that can infect all homeothermic animals. The occurrence of antibodies against $\boldsymbol{T}$. gondii in back yard chicken, from rural properties of Jaguapitã county, Paraná State, Brazil was studied, serun samples were analysed by Indirect Immunofluorescence Assay (IFA). Titers higher or equal to 16 were considered positives. A total of 155 sera were studied, $16(10.3 \%)$ of which were positive to $\boldsymbol{T}$. gondii, whereas $139(89.7 \%)$ were non-reactive. The most frequent titers were $64(5 / 31.2 \%) ; 16(4 / 25 \%)$ and 1024 (4/25\%); whereas the highest titer was 1024 (4/25\%). The seropreavlence of $\boldsymbol{T}$. gondii was not influenced by avian sex (Fisher exact $p=0.12$ ), by the avian purpose (fisher exact $p=0.39$ ), by the percentage of positive cats in the same property $(r=-0.19 p=0.27)$, nor by the number of positive cats $(r=-0.09 p=0.60)$. The present work showed a high occurrence of antibody against $\boldsymbol{T}$. gondii in domestic chicken from rural properties in Jaguapitã county. These animals may be source of infection to human beings and to other animals when consumed raw or semiraw.

Key words: toxoplasmosis in chicken, seroprevalence, seroepidemiology, Toxoplasma gondii.

\section{INTRODUÇÃO}

O Toxoplasma gondii é um protozoário heteroxeno, que pode infectar uma grande variedade de espécies de mamíferos, aves, anfíbios e répteis (SANCHIS, 1978), sendo considerada uma das para-

\footnotetext{
${ }^{1}$ Projeto financiado pela CPG-UEL/CAPES/CNPq.

${ }^{2}$ Médico Veterinário da Secretaria de Saúde do Município de Jaguapitã, PR.

${ }^{3}$ Professor, Doutor do Departamento de Medicina Veterinária Preventiva, Universidade Estadual de Londrina (UEL), CP 6001, 86050970 Londrina, PR, Brasil. E-mail: italmar@uel.br. Autor para correspondência.

${ }^{4}$ Medico Veterinário, mestrando de Sanidade Animal, UEL.

${ }^{5}$ Medico Veterinário, Departamento de Medicina Veterinária Preventiva, UEL. 
sitoses mais freqüentes no homem e talvez nos animais homeotérmicos (APTL, 1973). Os felinos são a chave na transmissão da doença (DUBEY et al., 1995) pois juntamente com os demais felídeos são os únicos que eliminam os oocistos pelas fezes (FRENKEL et al., 1970).

Galinhas oriundas de pequenas criações podem conter cistos teciduais de Toxoplasma gondii, representando risco de infecção para o homem, principalmente quando manipulam carnes cruas sem muita higiene ou através do consumo de carnes cruas ou semicozidas (LITERAK \& HEJLICEK, 1993).

Essas colocações corroboram com os estudos de KANETO (1995) que, trabalhando com inoculação experimental do $\boldsymbol{T}$. gondii em frangos de corte, isolou o parasita de vários órgãos, inclusive coração e musculatura esquelética, sugerindo a importância dessa espécie na disseminação da doença. Da mesma forma, MEDEIROS \& LOPES (1996), avaliando 11 galinhas criadas em condições naturais no município de Soropédica, Rio de Janeiro, isolaram o $\boldsymbol{T}$. gondii em coração e cérebro de uma delas. DUBEY et al. (1993), estudando o T. gondii através de inoculações experimentais em galinhas, confirmaram que esses animais podem desenvolver anticorpos para a toxoplasmose, bem como exibiram cistos teciduais em cérebro, coração e musculatura dessas aves.

ARAUJO et al. (1989), estudando a toxoplasmose em frangos de corte encaminhados para abatedouros na grande Porto Alegre, descreveram a necessidade de determinar-se a importância das galinhas criadas em fundo de quintal para a epidemiologia dessa enfermidade.

GARCIA (1998), avaliando a toxoplasmose em propriedades rurais no município de Jaguapitã, observou uma elevada prevalência nas populações de animais domésticos (suínos, bovinos, ovinos e equinos), de companhia (cães e gatos) e em humanos. Essa situação característica da epidemiologia do $\boldsymbol{T}$. gondii na região, suscitou a necessidade de estudar as galinhas domésticas. Dessa forma, o objetivo do presente estudo foi avaliar a soroprevalência da toxoplasmose em galinhas (Gallus gallus domesticus) criadas em fundo de quintal de propriedades rurais do município de Jaguapitã

\section{MATERIAL E MÉTODOS}

O município de Jaguapitã, localizado ao norte do Estado do Paraná, com 10613 habitantes, 3142 desses na zona rural (IBGE, 1991), apresenta uma altitude de $650 \mathrm{~m}$, latitude $23^{\circ}$ sul e longitude $51^{\circ} \mathrm{W}-\mathrm{GR}$, um clima subtropical úmido mesotérmi- co, com $463,138 \mathrm{Km}^{2}$ (IPARDES, 1991). A população estimada de galinhas criadas em fundo de quintal na zona rural do município, foi de 15710 aves (cinco aves para cada habitante da zona rural).

Fizeram parte do estudo 40 propriedades sorteadas ao acaso de um total de 506 imóveis rurais (INCRA, 1995). Das 40 propriedades, 32 apresentavam criações de galinhas de fundo de quintal (corte e postura) de onde foram colhidas, ao acaso, 155 amostras de sangue para proceder-se o estudo. O sangue foi obtido por punção venosa $(2 \mathrm{~m} \ell)$ em tubos de ensaio, colocado em banho maria a $37^{\circ} \mathrm{C}$ por duas horas até retração do coágulo e centrifugado a $1560 \mathrm{~g}$ durante 15 minutos. Após, o soro foi retirado com pipeta de pasteur, transferido para frascos estéreis, identificado e armazenado a $-20^{\circ} \mathrm{C}$ até realização dos exames.

Todas as amostras colhidas foram acompanhadas de uma ficha epidemiológica, que contemplou número da propriedade, identificação da amostra, sexo e finalidade da criação das aves, presença de felinos, bem como consumo de carne e ovos das aves pelos moradores.

Os soros foram submetidos à reação de imunofluorescência indireta (RIFI) para detecção de anticorpos anti-Toxoplasma gondii da classe $\mathrm{IgG}$, conforme técnica descrita por CAMARGO (1964), utilizando-se taquizoítos da cepa RH com antígeno adsorvido à lâmina, e conjugado anti-IgG de galinhas (Sigma-Chemical) marcado com fluoresceína (FITC). A leitura foi realizada em microscópio de epiluminescência da marca NIKON. Incluíram-se para todas as reações soros padrões positivo e negativo previamente conhecidos.

A positividade foi considerada para aquelas diluições maiores ou iguais a 1:16. Foi utilizado o teste Exato de Fisher e o de correlação para verificar a associação entre a soroprevalência e os fatores de risco da enfermidade. A associação ou correlação foram consideradas significantes quando $\mathrm{p} \leq \mathrm{a} 0,05$.

\section{RESULTADOS}

Das 155 amostras de soro das galinhas de criações domésticas, das 32 propriedades rurais estudadas no município de Jaguapitã, 16 (10,3\%) foram reagentes ao $\boldsymbol{T}$. gondii, e 139 (89,7\%) não reagentes, conforme observa-se na tabela 1 . Os títulos de anticorpos obtidos pela RIFI foram; 16 (4/25\%), $64(5 / 31,2 \%), 256(3 / 18,8 \%)$ e 1024 $(4 / 25 \%)$. O estudo epidemiológico não revelou efeito significativo do fator sexo das aves (Exato de Fisher $\mathrm{p}=0,12$, tabela 1 ) nem do fator finalidade da criação (corte ou postura, Exato de Fisher $p=0,39$, tabela 2) sobre a soroprevalência de $\boldsymbol{T}$. gondii. 
Tabela 1 - Detecção de anticorpos anti-Toxoplasma gondii através da reação de imunofluorescência indireta-IgG (RIFI) em soros de galinhas de criações domésticas oriundas de propriedades rurais, correlacionadas ao sexo, no município de Jaguapitã, Paraná, Brasil, 1997.

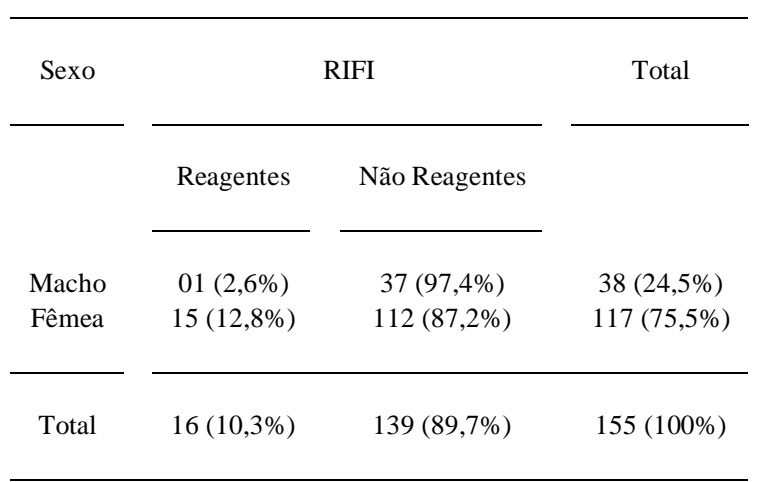

Exato de Fisher $\mathrm{p}=0,12$.

Em relação às propriedades estudadas, 12 (37,5\%) apresentaram animais soropositivos ao $\boldsymbol{T}$. gondii, e $20(62,5 \%)$ não revelaram respostas sorológicas positivas, através da RIFI, sendo que a soropositividade nas aves variou de 0 a $80 \%$, conforme observa-se na tabela 3 .

O estudo da correlação entre as percentagens de aves sororeagentes (estudo atual) e as percentagens de humanos e felinos sororeagentes (GARCIA,1998) para a toxoplasmose, segundo as propriedades estudadas, não revelaram correlações significativas entre aves e felinos $(r=-0,19 p=0,27)$ nem entre aves e humanos $(r=-0,19 p=0,29)$, conforme tabela 4. O estudo da correlação entre as quantidades de felinos reagentes e as percentagens das aves sororeagentes também não revelou associação significativa $(r=-0,09 \quad \mathrm{p}=0,60)$, conforme exposto na tabela 4.

O estudo atual revelou uma alta prevalência da toxoplasmose $(10,3 \%)$ em galinhas (Gallus gallus domesticus) de criações de fundo de quintal, oriundas de propriedades rurais, quando comparado aos estudos de ARAUJO et al. (1989), que verificaram uma prevalência de $2,8 \%$, através da prova de hemaglutinação indireta em frangos abatidos em matadouros de Porto Alegre, Rio Grande do Sul, bem como ao observado por LITERAK \& HEJLICEK (1993) que, estudando a toxoplasmose em aves da República Tcheca, verificaram prevalências de 5,1\% (169/3338) em galinhas criadas em pequenas criações e $0,01 \%$ (1/1120) para galinhas criadas em escala industrial, através da prova de Sabin-Feldman.

Essas diferenças em relação à literatura, podem refletir níveis diferentes de infectividade nos ecossistemas estudados, ou níveis diferentes de sen- sibilidade nas técnicas utilizadas. Os achados de DUBEY et al. (1993) reforçam esta última possibilidade quando, comparando as provas de aglutinação em látex, aglutinação indireta, Sabin-Feldman, aglutinação modificada e ELISA, verificam que apenas as provas de aglutinação modificada e ELISA foram sensíveis para detectar o $\boldsymbol{T}$. gondii em galinhas. Outros autores também verificaram a baixa sensibilidade da prova de Sabin-Feldman nessa espécie (LITERAK \& HEJLICEK, 1993; Ruiz \& Frenkel, 1980, apud FRENKEL, 1981).

No presente trabalho, a reação de imunofluorescência indireta demonstrou ser eficiente para detectar anticorpos anti-T. gondii nas aves, porém, maiores estudos devem ser realizados para avaliar a sua sensibilidade nessa espécie.

Os testes de correlação entre as percentagens das aves reagentes e as dos humanos e felinos residentes nas mesmas propriedades não revelaram correlações significativas, demonstrando que não ocorreram relações entre as percentagens de humanos reagentes com as percentagens de aves reagentes, nem entre as percentagens de felinos reagentes com as das aves.

WEIGEL et al. (1995) descreveram que a quantidade é mais importante que a percentagem de gatos infectados, pelo fato desses animais eliminarem milhões de oocistos com as fezes, que se acumulam no meio ambiente. Dessa forma, o estudo comparativo entre a quantidade de felinos reagentes e a soroprevalência das aves foi calculado, e não revelaram correlações significativas. Entretanto, nas propriedades estudadas, a presença de felinos era frequiente, e em um estudo sorológico desses animais, observou-se que $73 \%$ eram sororeagentes ao

Tabela 2 - Detecção de anticorpos anti-Toxoplasma gondii através da reação de imunofluorescência indireta-IgG (RIFI) em soros de galinhas de criações domésticas oriundas de propriedades rurais, correlacionadas à finalidade de criação (corte ou postura), no município de Jaguapitã, Paraná, Brasil, 1997.

\begin{tabular}{|c|c|c|c|}
\hline \multirow[t]{2}{*}{ Finalidade } & \multicolumn{2}{|c|}{ RIFI } & \multirow[t]{2}{*}{ Total } \\
\hline & Reagentes & Não Reagentes & \\
\hline Corte & $03(6,5 \%)$ & $43(93,5 \%)$ & $38(29,7 \%)$ \\
\hline Postura & $13(11,9 \%)$ & $112(88,1 \%)$ & $117(70,3 \%)$ \\
\hline Total & $16(10,3 \%)$ & $139(89,7 \%)$ & $155(100 \%)$ \\
\hline
\end{tabular}

Exato de Fisher $\mathrm{p}=0,39$. 
Tabela 3 - Distribuição das galinhas (Gallus gallus domesticus) de criações domésticas, correlacionadas à distribuição da população humana e felina, examinadas através da reação de imunofluorescência indireta-IgG, para detecção de anticorpos anti-Toxoplasma gondii, segundo a propriedade, número de animais examinados, número de animais reagentes e respectivas percentagens de reagentes, da área rural do município de Jaguapitã, Paraná, Brasil, 1997.

\begin{tabular}{|c|c|c|c|c|c|c|c|c|c|}
\hline \multirow[t]{2}{*}{ Propriedade } & \multicolumn{3}{|c|}{ Galinhas } & \multicolumn{3}{|c|}{ Felinos } & \multicolumn{3}{|c|}{ Humanos } \\
\hline & Total & Números Positivos & $\%$ & Total & Números Positivos & $\%$ & Total & Números Positivos & $\%$ \\
\hline 01 & 10 & 01 & 10 & 01 & 01 & 100 & 06 & 02 & 33 \\
\hline 02 & 03 & 01 & 33,3 & 03 & 03 & 100 & 06 & 03 & 50 \\
\hline 03 & 05 & 01 & 20 & 0 & 0 & 0 & 04 & 0 & 0 \\
\hline 04 & 05 & 04 & 80 & 0 & 0 & 0 & 04 & 03 & 75 \\
\hline 05 & 05 & 0 & 0 & 05 & 03 & 60 & 08 & 06 & 75 \\
\hline 06 & 03 & 01 & 33,3 & 02 & 02 & 100 & 04 & 02 & 50 \\
\hline 07 & 03 & 0 & 0 & 01 & 01 & 100 & 20 & 17 & 85 \\
\hline 08 & 09 & 0 & 0 & 11 & 05 & 45 & 24 & 24 & 100 \\
\hline 09 & 03 & 01 & 33,3 & 03 & 03 & 100 & 04 & 02 & 50 \\
\hline 10 & 03 & 02 & 66,6 & 04 & 02 & 50 & 07 & 03 & 42,8 \\
\hline 11 & 03 & 0 & 0 & 03 & 03 & 100 & 10 & 09 & 90 \\
\hline 12 & 03 & 01 & 33,3 & 05 & 01 & 20 & 09 & 03 & 33 \\
\hline 13 & 05 & 01 & 20 & 01 & 01 & 100 & 07 & 04 & 57 \\
\hline 14 & 06 & 0 & 0 & 01 & 0 & 0 & 03 & 02 & 66 \\
\hline 15 & 05 & 01 & 20 & 02 & 02 & 100 & 05 & 04 & 80 \\
\hline 16 & 05 & 0 & 0 & 01 & 01 & 100 & 04 & 02 & 50 \\
\hline 17 & 05 & 0 & 0 & 08 & 07 & 87,5 & 04 & 04 & 100 \\
\hline 18 & 05 & 0 & 0 & 03 & 02 & 66 & 03 & 01 & 33 \\
\hline 19 & 09 & 0 & 0 & 0 & 0 & 0 & 05 & 02 & 40 \\
\hline 20 & 05 & 0 & 0 & 01 & 01 & 100 & 04 & 02 & 50 \\
\hline 21 & 05 & 0 & 0 & 01 & 01 & 100 & 11 & 04 & 36,4 \\
\hline 22 & 05 & 01 & 20 & 30 & 25 & 83 & 59 & 49 & 83 \\
\hline 23 & 05 & 0 & 0 & 20 & 18 & 90 & 40 & 19 & 47,5 \\
\hline 24 & 04 & 0 & 0 & 06 & 01 & 16 & 08 & 0 & 0 \\
\hline 25 & 07 & 0 & 0 & 10 & 06 & 60 & 15 & 14 & 93 \\
\hline 26 & 05 & 01 & 20 & 04 & 02 & 50 & 02 & 01 & 50 \\
\hline 27 & 03 & 0 & 0 & 0 & 0 & 0 & 02 & 02 & 100 \\
\hline 28 & 05 & 0 & 0 & 09 & 09 & 100 & 03 & 03 & 100 \\
\hline 29 & 03 & 0 & 0 & 07 & 04 & 57 & 03 & 02 & 66 \\
\hline 30 & 06 & 0 & 0 & 06 & 03 & 50 & 06 & 05 & 83 \\
\hline 31 & 04 & 0 & 0 & 03 & 03 & 100 & 05 & 04 & 80 \\
\hline 32 & 03 & 0 & 0 & 02 & 01 & 50 & 04 & 03 & 75 \\
\hline
\end{tabular}

T. gondii (GARCIA, 1998). LITERAK \& HEJLICEK (1993) consideram que os felinos podem representar um foco permanente de infecção toxoplásmica para as aves. A aparente contradição dos dados deste trabalho com a literatura pode estar relacinada ao fato que não é hábito da população o consumo de aves cruas ou mal cozidas, bem como a maioria das propriedades em estudo $(20 / 62,5 \%)$ não apresentaram aves sororeagentes ao T. gondii.

O papel das criações de galinhas em escala industrial, na transmissão toxoplásmica para humanos, é de pequena importância, devido ao sistema de criação ser rápido e não permitir o contato com felinos, porém, contrasta com a criação domés- tica em pequena escala, onde as aves permanecem durante anos convivendo no mesmo ecossistema (ARAUJO et al., 1989; LITERAK \& HEJLICEK, 1993).

Através do presente trabalho, demonstrou-se uma soropositividade elevada para o $\boldsymbol{T}$. gondii em galinhas de criações domésticas, oriundas de propriedades rurais do município de Jaguapitã, porém os estudos de correlação demonstraram um baixo risco de associação entre as infecções humana e de aves. Entretanto, sugerem-se mais estudos, quanto às técnicas de diagnóstico e ao potencial da carne e ovos dessas aves em transmitir zoonose aos seres humanos da zona urbana e rural. 
Tabela 4 - Resultado das correlações obtidas entre a distribuição das percentagens de sororeagentes ao Toxoplasma gondii em galinhas, humanos e felinos, e a quantidade de felinos positivos correlacionados a percentagem de aves sororeagentes, de acordo com a propriedade estudada, município de Jaguapitã, Paraná, Brasil, 1997.

\begin{tabular}{lccc}
\hline & $\begin{array}{c}\text { Percentagem de aves sororea- } \\
\text { gentes }\end{array}$ & $\begin{array}{c}\text { Percentagem de felinos sororea- } \\
\text { gentes }\end{array}$ & $\begin{array}{c}\text { Percentagem de humanos sororea- } \\
\text { gentes }\end{array}$ \\
\cline { 2 - 3 } $\begin{array}{l}\text { Percentagem de aves sororeagen- } \\
\text { tes }\end{array}$ & $\mathrm{r}=1,00$ & $\mathrm{r}=-0,19$ & $\mathrm{r}=-0,19$ \\
Quantidade de felinos sororea- & $\mathrm{p}=0,00$ & $\mathrm{p}=0,29$ & $\mathrm{p}=0,27$ \\
gentes & $\mathrm{r}=-0,09$ & $\mathrm{r}=0,27$ & $\mathrm{p}=0,27$ \\
& $\mathrm{p}=0,60$ & $\mathrm{p}=0,13$ & $\mathrm{p}=0,12$ \\
\hline
\end{tabular}

$\mathrm{r}=$ coeficiente de correlação $\mathrm{p}=$ significância para $\leq 0,05$.

\section{REFERÊNCIAS BIBLIOGRÁFICAS}

APTL W., THERMANN E., NIEDMAN, G $\boldsymbol{e}$ t al.. Toxoplasmosis. Santiago: Arancibia Horns, 1973. 160 p.

ARAUJO F.A.P. SILVA N.R.S., CHAPLIN E.L. et al.. Prevalência de anticorpos toxoplásmicos em frangos abatidos para consumo humano em Porto Alegre, Rio Grande do Sul. Arq Fac Vet UFRGS, v. 17, p. 23-28, 1989.

CAMARGO M.E. Improved technique of indirect imunofluorescence for serological diagnosis of toxoplasmosis. Rev Inst Med Trop São Paulo, v. 6, n. 3, p. 117-118, 1964.

DUBEY J.P. LAPPIN M.R., THULLIEZ P. Long term antibody responses of cat fed Toxoplasma gondii tissue cysts. J Parasitology, v. 81, n. 6, p. 887-893, 1995.

DUBEY J.P., RUFF M.D., CAMARGO M.E. et al. Serologic and parasitologic responses of domestic chickens after oral inoculation with Toxoplasma gondii oocysts. Am J Vet Res, v. 54, n. 10, p. 1668-1672, 1993.

FRENKEL J.K. False-negative serologic test for toxoplasma in birds. J Parasitology, v. 67, n. 6, p.952-953, 1981.

FRENKEL J.K., DUBEY J.P., MILLER N.L. Toxoplasma gondii in cats fecal stages identified as coccidian oocysts. Science, $n$. 167, p. 893-896, 1970.

FUNDAÇÃO INSTITUTO BRASILEIRO DE GEOGRAFIA E ESTATÍSTICA (IBGE). Sinopse preliminar do Censo demográfico: resultados do universo relativos às características da população e dos domicílios, Paraná. n. 20, Rio de Janeiro: IBGE, 1991.

GARCIA J.L. Epidemiologia do Toxoplasma gondii na população humana e animal dentro do ecossistema da doença.
Londrina-PR, 1998. 72 p. Dissertação (Mestrado em Sanidade Animal) - Curso de Pós-graduação em Sanidade Animal, Universidade Estadual de Londrina, 1998.

INSTITUTO NACIONAL DE COLONIZAÇÃO E REFORMA AGRÁRIA (INCRA). Relação de certificados e cadastros e notificação de imóveis rurais emitidos, 714151-Jaguapitã, Paraná: Brasília: INCRA, 1995.

INSTITUTO PARANAENSE DE DESENVOLVIMENTO ECONÔMICO E SOCIAL (IPARDES). Caderno de estatísticas municipal. Jaguapitã: IPARDES, 1991.

KANETO C.N. Infecção experimental de frangos de corte com oocistos, cistos e taquizoítos de Toxoplasma gondii (Nicolle \& Manceaux, 1908) Nicolle \& Manceaux, 1909. Jaboticabal - SP, 1995. Dissertação (Mestrado) - Faculdade de Ciências Agrárias e Veterinárias campus de Jaboticabal, Universidade Estadual de São Paulo, 1995.

LITERÁK I., HEJLÍCEK K. Incidence of Toxoplasma gondii in population of domestic birds in the Czech Republic. Avian Pathology, v. 22, p. 275-281, 1993.

MEDEIROS S.M., LOPES C.W.G. Pleomorfismo de uma amostra acistogênica de Toxoplasma gondii Nicolle \& Manceaux, 1909 (Apicomplexa: Toxoplasmatinae) isolada de uma galinha naturalmente infectada. Rev Bras Med Vet, v. 18, n. 2, p. 71-73, 1996.

SANCHIS F.S. Estudo da Reinfecção Experimental do gato pelo Toxoplasma gondii. São Paulo-SP, 1978. Tese (Livre Docente) - Faculdade de Medicina Veterinária e Zootecnia, Universidade Estadual de São Paulo, 1978.

WEIGEL R.M. DUBEY J.P., SIEGEL A.M. et al. Risk factors for transmission of Toxoplasma gondii on swine farms in Illinois. J Parasitology, v. 81, n. 5, p. 736-741, 1995.

Ciência Rural, v. 30, n. 1, 2000. 